Many of the bheels have been brought into cultivation and planted with tea, and one of the greatest problems in connection with the cultivation of these areas has been the removal of the enormous amount of water which accumulates in such places during the rainy season, for, in addition to the fact that more than 100 in. of rain may fall on the area in the course of five months, much of the drainage-water from the surrounding hillocks finds its way into the bheels. To this end it has been a common practice to dig an exceedingly wide and deep drain along the lowest part of the bheel, which is generally near the centre, and to drain into this from the edges. In this way the excess water is got rid of in the rainy season, but there has been an attendant disadvantage, in that the bheels are often dried out completely during the dry season. This occurs to such an extent that the crop-yielding period is often unduly shortened, and in many places it is a common practice to block up the mouths of the drains at the end of the rains to prevent excessive drying-out and prolong the period of yield.

Further, during the dry period the bushes are pruned and the land hoed clean, and the area thus loses its protective covering of foliage and weeds.

In such circumstances, in which the dried-out area is fully exposed to the sun's rays, spontaneous combustion in the soil is of common occurrence, and the soil becomes uncomfortably hot to walk on even in heavy boots.

Many acres of tea have been killed out in this way, but no ignition of the bushes occurs above ground, and it is questionable if jungle fires ever originate in this way, for it is only in the exceptional circumstances outlined above that the phenomenon has been found to occur.

E. A. ANDREWS.

Indian Tea Association, Tocklai Experimental

Station, Cinnamara, Assam, December I4.

\section{Microscope Illumination and Fatigue.}

Mr. BARNARD's letter in NATURE of December 29 last, p. 566 , is unusually dogmatic as a contribution to a scientific discussion. As the title of this correspondence indicates, the original letter was written, not so much to direct attention to a particular method as to a general principle, with the intention of increasing the comfort of workers who have to work long hours at the microscope. It appears that $\mathrm{Mr}$. Barnard has arrived at the same principle independently, but in a case of this nature there is no excuse for withholding from publication a matter which affects the well-being of a large number of workers.

Mr. Barnard condemns the method employed, but perhaps without having given the svstem described an unprejudiced trial. The ultimate test of any method lies in actual practice. Before publication the resistance-controlled illumination was tested out completely within the limits stated, imposed by the use of light-filters and the nature of the work of this laboratory. Since Mr. Barnard brought up the question of the shift of the dominant radiation--which was irrelevant at the time-further tests have been made with the unscreened light (which is never used for critical work here), and it was found that there was no perceptible loss of resolution or colour differentiation with the lowering of the current. The shift of the dominant is thus not a cause for alarm. A further test showed that to produce equivalent results with neutral filters some eight or ten screens would have to be made, and even then the optimum for every small variation of staining or thickness of section could not be obtained. Such an outfit, with the large amount of experiment and adjustment necessary to get the screens even approximately right, would be quite out of reach of most workers, and could not be conveniently standardised. Further troubles enter with small alterations in the light source due to age and variation of voltage, the general illumination of the laboratory, and, not least, the personal equation. H. J. Denham.

Shirley Institute, Didsbury, January 4.

\section{Tin Plague and Arctic Relics.}

REFERRING to the letter on tin plague in Nature of December is last, it may be of interest to record that in the Museum of Fisheries arid Shipping at Hull, among a number of Arctic and Antarctic relics, we have two tins, each about 6 in. in diameter, provided with a thin iron handle on the top soldered on to assist in carrying. These tins, according to the "Guide to the Museum of the Hull Literary and Philosophical Society," published in I860, and confirmed by that society's minutes, were picked up, among other relics and stores left by Capt. Parry, on Fury Beach in 1825. They were found by Capt. (afterwards Sir John) Ross in I83I, who brought them away with him. Capt. Ross was picked up at sea in a boat by Capt. Humphreys, of the Isabella, a whaler of Hull, in 1833, and these relics, among others, were in the boat with him. They were brought to Hull and given to the Literary and Philosophical Society. Eventually this society's collection was handed to the Hull Corporation.

About ten years ago I was curious to know the contents of these two tins, and had them opened; one was found to be full of corned beef in excellent colour and condition, and the other contained peasoup. Both seemed to be quite fresh, and my attendant sampled them and stated that they were quite good and sweet. He still lives. The soup and the meat are now exhibited in glass jars, and are still in good condition.

My object in mentioning these facts is to show that after being left in the Arctic between $1825-3 \mathrm{I}$, and then taken charge of for another two years by Capt. Ross, which means that they were more or less subject to Arctic conditions for eight years, and then having been in Hull for eighty years, the metal does not seem to have deteriorated in any way and it had had no effect upon the contents. Possibly this may be due to the fact that the tins were painted with a thick coat of yellow and green paint respectively, which may have prevented any "plague." If this is the cause, the circumstances may be of value on future expeditions of this character.

The Museum, Hull.

T. SHEPPARD.

\section{Inheritance of a Cheek-Mole.}

PrRHAPS the following case of the inheritance of a mole on the cheek for three generations may be interesting. Records do not go back any further, but, as the representative of the present generation is nineteen, it may be possible to see whether it is continued. The grandfather had a peculiar mole right in the middle of his left cheel. Of his children, two daughters both showed it in almost the same position. The sons did not, but one daughter of one son now has it. There are two boys and two girls in family, but it has appeared only on one girl.

G. W. HARRIS.

The Royal Automobile Club, London, S.W.I, December 25.

NO. 2725 , VOL. IO9] 